\title{
Scientific substantiation of medico-social prevention of digestive diseases in schoolchildren on the basis of the prediction table
}

\author{
M. A. Buleshov' ${ }^{1}$ A. M. Buleshova', S. A. Tuktibayeva', A. A. Zhaksylyk², B. O. Ashirov², A. K. llimova², U. Yu. Chulpanov³
}

\begin{abstract}
In the present work presents the results of scientific substantiation of medico-social preventive the disease of the digestive system at school students conducted on the basis of the prediction table. The development of a prognostic matrix for predicting the occurrence and development of diseases of the digestive system in schoolchildren was carried out according to a comprehensive socio-hygienic study of schoolchildren and the study of the prevalence of diseases of the digestive system according to medical examinations among schoolchildren. The influence of socio-hygienic and medicobiological factors on the occurrence and development of digestive diseases in schoolchildren was studied. To do this, we have compiled a special map of the study of socio-hygienic and biomedical factors for the formation of diseases of the digestive system, which includes 28 factors and 84 of their gradations. It was calculated all the parameters for the preparation of a prognostic matrix to assess the occurrence of diseases of the digestive system in schoolchildren by socio-hygienic and medico-biological risk factors. Taking into account the great importance of the prognostic coefficient for Pediatrics and gastroenterology, it was developed ready-made threshold values of the prognostic index that characterize the probability of the risk of digestive diseases in schoolchildren.
\end{abstract}

Keywords: factors, medical and social, relative risk, digestive disease, prognostic table, trade values

\section{INTRODUCTION}

Health of children and adolescents is of significant medical and social importance, which is determined not only by the increasing proportion of chronic diseases, but also the magnitude of economic losses of society in the future. Changes in the health of schoolchildren, often of a negative nature in recent years, cause the greatest concern (1). During the years of schooling, the number of children with visual impairment has increased 10 times, up to $70 \%$ of schoolchildren have musculoskeletal disorders, the number of children with mental health disorders has increased 4 times, and 3 times - with diseases of the digestive system. More than $60 \%$ of adolescent girls need gynecological care, more than half of young men of military age have a delay from conscription for health reasons (2). All of these negative trends develop on the background of reducing the volume of preventive measures, increased school load, the deterioration of the conditions of training and education, structure and organization of nutrition of children and adolescents, decreasing their physical fitness, reducing physical culture and sports, the closing of the institutions concerned $(1,3)$.

Nutritional disorders in children are one of the reasons for the high incidence of digestive diseases, which occupy the first place (10-12\%) in the structure of morbidity in schoolchildren, as well as in the occurrence of anemia and metabolic diseases, the prevalence of which has increased significantly in recent years (10-15\% of school-age children). Approximately $10 \%$ of children have a low body weight or reduced growth, which indicates an acute or a chronic malnutrition (4).

Based on the high prevalence of diseases of the digestive system among children, especially in school-age children, it is necessary to emphasize the growing relevance of the development and implementation of prevention of diseases

\footnotetext{
Khoja Akhmet Yassawi International Kazakh-Turkish University, Turkestan, Kazakhstan.

2 Kazakhstan's Medical University «KSPH», Almaty, Kazakhstan.

3 Asfendiyarov Kazakh National Medical University, Almaty, Kazakhstan.
}

Correspondence: M. A. Buleshov

Khoja Akhmet Yassawi International Kazakh-Turkish University, Turkestan, Kazakhstan.

Received: 16 Jul 2019, Accepted: 4 Dec 2019

(C) 2019 by the authors; licensee Modestum Ltd., UK. This article is an open access article distributed under the terms and conditions of the Creative Commons Attribution License (http://creativecommons.org/licenses/by/4.0/). 
of the digestive system in schoolchildren. Therefore, in order to organize the prevention of diseases of the digestive system in schoolchildren, improve the performance of the school pediatrician and dispensary work of the district pediatrician, it is necessary to predict the onset of diseases of the digestive system in schoolchildren by socio-hygienic and medical-biological risk factors.

\title{
THE PURPOSE
}

The purpose of this work is to develop a prognostic matrix for predicting the occurrence and development of diseases of the digestive system in schoolchildren.

At the first stage, it was conducted a comprehensive socio-hygienic study of schoolchildren, conducted a study of the prevalence of diseases of the digestive system according to medical examinations among schoolchildren. The object of the study were students of 0-11 grades of five schools in Shymkent. The volume of the study was 1025 students.

Collection of information was carried out by the method of questioning students using a specially designed questionnaire "Medical, social and hygienic characteristics of the child."

A comprehensive social and hygienic study of schoolchildren of five schools in Shymkent showed that there are numerous factors that can negatively affect the health and affect the level of morbidity of the digestive system of schoolchildren. Thus, $24.9 \%$ of the surveyed schoolchildren live in conditions with a low level of material security, $0.9 \%$ live in poor housing conditions; $29.1 \%$ of schoolchildren are brought up in single-parent families; in $34 \%$ of cases, only one person works in the family, $11 \%$ of parents do not allocate money for the child's food at school; $4.3 \%$ of secondary school students and $8.2 \%$ of high school students smoke; $10.3 \%$ of secondary school students and $14.6 \%$ of high school students drink alcohol; $2.25 \%$ have an unfavorable psychological climate in the family; $34.9 \%$ have conflicts with classmates; $7.1 \%$ of primary school students, $20.3 \%$ - middle school and $17.1 \%$ - high school do not eat hot meals (excluding tea, coffee and other hot drinks) at school; $9.7 \%$ of primary school students, $30.6 \%-$ middle school and $35 \%$ - high school do not eat in the dining room and more often snack in the cafeteria.; $28 \%$ of respondents consider themselves not informed in matters of proper nutrition. Our studies have shown that the incidence of digestive diseases among students, according to medical examinations, during their studies at school increased by 1.4 times (from 105.9\% in primary school to $145.3 \%$ in high school). The ranking distribution of digestive diseases in schoolchildren, according to medical examinations, was as follows (Figure 1): first place - dyskinesia of the cystic duct and gallbladder - 40\%; second - chronic gastritis - 19\%; third - chronic cholecystitis, cholecystocholangitis - 18.5\%; fourth - chronic duodenitis $-12.5 \%$; fifth - functional disorders of the stomach - $7 \%$.

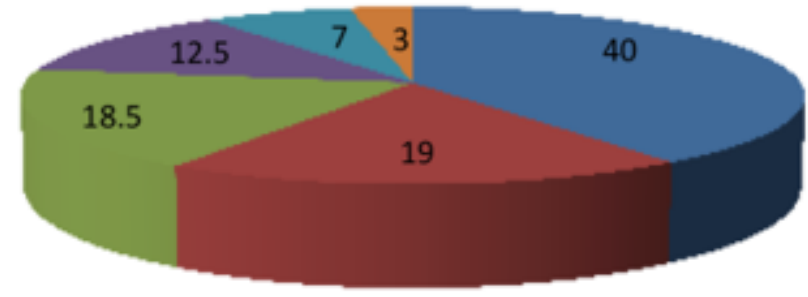

\author{
Dyskinesia of the cystic duct
and gallbladder \\ n Chronic gastritis \\ E Chronic cholecystitis, \\ cholecystocholangitis \\ n Chronic duodenitis
= Functional disorders of the stomach \\ E Other
}

Figure 1: The structure of digestive diseases in students, according to medical examinations (\%)

At the second stage, the influence of socio-hygienic and biomedical factors on the occurrence and development of diseases of the digestive system in schoolchildren was studied. To do this, we have compiled a special map of the study of socio-hygienic and biomedical factors for the formation of diseases of the digestive system, which includes 28 factors and 125 of their gradations.

The study of the influence of socio-hygienic and biomedical factors was carried out using a single-factor analysis of variance. Initially, 18 single-factor dispersion complexes were composed of 28 characteristics taken for the study. As a result, it was found that the most significant were the following factors: there are diseases of the digestive system among the next of kin - $\eta^{2}=16.3 \%$; uses alcohol $-\eta_{2}=14.2 \%$; does not eat hot meals at school $-\eta 2=11.5 \%$; experiences and 
worries in the event of stress, conflict situations at school - $\eta 2=7.1 \%$; snacks in the buffet instead of a full meal in the dining room or uses sandwiches $-\eta 2=6.8 \%(P<0.05)$.

At the third stage, it was calculated all the parameters for the preparation of a prognostic matrix to assess the occurrence of digestive diseases in schoolchildren by socio-hygienic and medico-biological risk factors. The frequency of digestive diseases in schoolchildren was accepted as the evaluation criterion (the data were obtained at the first stage of the study). The obtained data on the frequency of digestive diseases in schoolchildren, expressed in coefficients, were used to predict digestive diseases in schoolchildren.

The degree of influence of gradations of each factor was determined by applying a weighting factor or relative risk index $(R)$, which is the ratio of the maximum intensity index $(C)$ to the minimum (d) within each specific factor $(R=c / d)$.

For example, according to our study, the risk of diseases of the digestive system in fact "living conditions": gradation "bad" amounted to 77.4, and "good" 48.6 per 1000 examined. The relative risk of diseases of the digestive system in this case is $R=77.4 / 48.6=1.59$. If the factor has no effect, this ratio will be equal to one. The higher this figure, the more significant factor for the occurrence of this pathology. In the same way, it was calculated indicators for all other factors. It is established that the socio-hygienic and medical-biological factors have different effects on the occurrence and development of diseases of the digestive system. Therefore, $\mathrm{R}$ so calculated are summed up. According to our data, $\sum R=37.61$. This amount is required to determine the risk range. Such data as the prognostic coefficient $(X)$ was identified and compiled in the form of a prognostic table.

Normalized intensive index (NII) was used to calculate X. NII find the next way. To determine the NII, it is necessary to know the indicator of the incidence of diseases of the digestive system per 1000 examined in this particular group (P) and the "normalizing" indicator $(M)$ characterizing the intensity of diseases of the digestive system in the entire study population. Thus, the defeat of the digestive organs in persons who consume alcohol was $76.9(P=76.9)$, and the defeat of the digestive organs in the whole population was $172.8(M=172.8)$, hence:

$$
\mathrm{NII}=172.8 / 76.9=0.44
$$

From this, a prognostic coefficient is obtained:

$$
\mathrm{X}=\mathrm{P} * \mathrm{NII}=76.9 * 0.44=33.83
$$

The prognostic coefficients calculated in this way are given in Table 1.

\begin{tabular}{|c|c|c|c|c|c|c|c|c|}
\hline № & Factors & Gradation of factors & $\begin{array}{l}\text { Morbidity DDS for } \\
1000 \text { children }\end{array}$ & OR & NII & $\begin{array}{c}\text { Predictive coefficient } \\
\text { values }\end{array}$ & $\begin{array}{l}\text { The prognosis for the } \\
\text { incidence of DDS }\end{array}$ & $\begin{array}{c}\text { Risk } \\
\text { probability }\end{array}$ \\
\hline \multirow{2}{*}{1} & \multirow{2}{*}{ Sex } & Male & 76.5 & \multirow{2}{*}{1.55} & 0.44 & 33.7 & unfavorable & most \\
\hline & & Female & 49.2 & & 0.25 & 13.77 & favorable & least \\
\hline \multirow{3}{*}{2} & \multirow{3}{*}{ Class } & 0-4 classes & 48.4 & \multirow{3}{*}{1.39} & 0.28 & 13.55 & favorable & least \\
\hline & & 5-8 classes & 54.5 & & 0.32 & 17.42 & favorable & least \\
\hline & & 9-11 classes & 67.4 & & 0.34 & 28.9 & unfavorable & most \\
\hline \multirow{2}{*}{3} & \multirow{2}{*}{ Brought up } & In a full family & 46.3 & \multirow{2}{*}{1.48} & 0.27 & 12.5 & favorable & least \\
\hline & & In a single-parent family & 68.7 & & 0.39 & 26.9 & less favourable & average \\
\hline \multirow{2}{*}{4} & \multirow{2}{*}{$\begin{array}{l}\text { The level of material security of } \\
\text { the family }\end{array}$} & Good & 48.9 & \multirow{2}{*}{1.47} & 0.28 & 13.7 & favorable & least \\
\hline & & Bad & 72.3 & & 0.42 & 30.4 & unfavorable & most \\
\hline \multirow{3}{*}{5} & \multirow{3}{*}{$\begin{array}{l}\text { Number of working family } \\
\text { members }\end{array}$} & One & 78.3 & \multirow{3}{*}{1.51} & 0.45 & 35.63 & unfavorable & most \\
\hline & & Two & 59.7 & & 0.34 & 20.34 & favorable & least \\
\hline & & Three & 51.7 & & 0.29 & 14.9 & favorable & least \\
\hline \multirow{2}{*}{6} & \multirow{2}{*}{$\begin{array}{l}\text { Psychological microclimate in } \\
\text { the family }\end{array}$} & Favorable & 49.1 & \multirow{2}{*}{1.36} & 0.28 & 13.7 & favorable & least \\
\hline & & Unfavorable & 67.1 & & 0.39 & 26.16 & less favourable & average \\
\hline \multirow{2}{*}{7} & \multirow{2}{*}{ Housing conditions } & Good & 48.6 & \multirow{2}{*}{1.59} & 0.28 & 13.6 & favorable & least \\
\hline & & Bad & 77.4 & & 0.45 & 34.83 & unfavorable & most \\
\hline \multirow{2}{*}{8} & \multirow{2}{*}{ Smoking } & Not smoke & 52.2 & \multirow{2}{*}{1.41} & 0.30 & 15.66 & favorable & least \\
\hline & & Smoke & 74.1 & & 0.42 & 31.12 & unfavorable & most \\
\hline \multirow{2}{*}{9} & \multirow{2}{*}{ Alcohol consumption } & No & 51.7 & \multirow{2}{*}{1.48} & 0.29 & 14.99 & favorable & least \\
\hline & & Yes & 76.9 & & 0.44 & 33.83 & unfavorable & most \\
\hline \multirow{2}{*}{10} & \multirow{2}{*}{$\begin{array}{l}\text { Conflicts with classmates and } \\
\text { schoolchildren }\end{array}$} & No & 54.6 & \multirow{2}{*}{1.39} & 0.32 & 17.47 & favorable & least \\
\hline & & Yes & 75.9 & & 0.43 & 32.63 & unfavorable & most \\
\hline \multirow{2}{*}{11} & How to respond to conflict & $\begin{array}{l}\text { Does not pay attention or gets } \\
\text { upset not much and forgets quickly }\end{array}$ & 48.6 & & 0.28 & 13.60 & favorable & least \\
\hline & situations & $\begin{array}{l}\text { Pays attention to them. very upset } \\
\text { and remembers for a long time }\end{array}$ & 76.5 & 1.57 & 0.44 & 33.67 & unfavorable & most \\
\hline & To eat hot meals (excluding & 2 times & 49.7 & & 0.29 & 14.41 & favorable & least \\
\hline 12 & tea, coffee and other hot & 1 time & 52.3 & 1.49 & 0.36 & 22.42 & less favourable & average \\
\hline & drinks) at school & no eating & 74.5 & & 0.43 & 32.03 & unfavorable & least \\
\hline
\end{tabular}

Table 1: Prognostic matrix for a comprehensive assessment of the risk of digestive diseases in schoolchildren 
Table 1 (continued): Prognostic matrix for a comprehensive assessment of the risk of digestive diseases in schoolchildren

\begin{tabular}{|c|c|c|c|c|c|c|c|c|}
\hline \multirow{3}{*}{\multicolumn{2}{|c|}{13 How to eat }} & Regularly in the dining room & 49.7 & \multirow{2}{*}{1.45} & 0.28 & 13.9 & favorable & most \\
\hline & & In the canteen or bring sandwiches & 61.7 & & 0.36 & 22.2 & less favourable & average \\
\hline & & no eating & 72.5 & & 0.42 & 30.45 & unfavorable & most \\
\hline \multirow{3}{*}{14} & & doesn't attend & 76.9 & \multirow{3}{*}{1.56} & 0.44 & 33.83 & unfavorable & most \\
\hline & How often visits the canteen & One time & 64.1 & & 0.37 & 23.72 & less favourable & average \\
\hline & & Two or more times & 49.2 & & 0.28 & 13.77 & favorable & least \\
\hline \multirow{3}{*}{15} & \multirow{3}{*}{$\begin{array}{l}\text { Do parents allocate money for } \\
\text { school meals }\end{array}$} & Yes & 49.1 & \multirow{3}{*}{1.58} & 0.28 & 33.74 & unfavorable & most \\
\hline & & Not always & 62.3 & & 0.36 & 22.42 & less favourable & average \\
\hline & & No & 77.6 & & 0.45 & 34.92 & unfavorable & most \\
\hline \multirow{3}{*}{16} & \multirow{3}{*}{$\begin{array}{l}\text { Does it take additional vitamin } \\
\text { and mineral complexes }\end{array}$} & 2 times a year & 48.9 & \multirow{3}{*}{1.52} & 0.28 & 13.69 & favorable & least \\
\hline & & 1 time per year & 61.3 & & 0.35 & 21.46 & less favourable & average \\
\hline & & No & 74.8 & & 0.43 & 32.16 & unfavorable & most \\
\hline \multirow{3}{*}{17} & \multirow{3}{*}{$\begin{array}{l}\text { Informed in matters of proper } \\
\text { nutrition }\end{array}$} & Yes & 49.6 & \multirow{3}{*}{1.56} & 0.28 & 13.88 & favorable & least \\
\hline & & Partially & 58.7 & & 0.34 & 19.95 & favorable & least \\
\hline & & No & 77.4 & & 0.45 & 34.83 & unfavorable & most \\
\hline \multirow{2}{*}{18} & \multirow{2}{*}{$\begin{array}{l}\text { Is there intolerance to certain } \\
\text { foods }\end{array}$} & No & 51.8 & \multirow{2}{*}{1.50} & 0.29 & 15.02 & favorable & least \\
\hline & & Yes & 78.1 & & 0.41 & 32.02 & unfavorable & most \\
\hline \multirow{2}{*}{\multicolumn{2}{|c|}{$\begin{array}{l}\text { The presence of diseases of the } \\
19 \text { digestive system among close } \\
\text { relatives (mother, father, } \\
\text { brother, sister) }\end{array}$}} & No & 48.4 & \multirow{2}{*}{1.61} & 0.28 & 13.55 & favorable & least \\
\hline & & Yes & 77.9 & & 0.45 & 35.05 & unfavorable & most \\
\hline
\end{tabular}

To determine the degree of influence of adverse factors on the occurrence and development of diseases of the digestive system, it is necessary to find prognostic coefficients corresponding to the gradation of each factor of a particular subject $(X)$, summarize them and divide them by the sum of the relative risk indicators for the listed gradations of factors $\left(\sum R\right)$, compare the result on the scale of the risk range and then determine the group of prognosis. Taking into account the great importance of the prognostic coefficient for Pediatrics and gastroenterology, we have developed ready-made threshold values of the prognostic index, characterizing the probability of the risk of digestive diseases in schoolchildren (Table 2).

Table 2: Threshold values of prognostic index characterizing the probability of risk of digestive diseases in schoolchildren

\begin{tabular}{ccc}
\hline Risk probability & The value of prognostic index & Predict the risk of diseases of the digestive system \\
\hline Least & $12.92-20.36$ & Favorable \\
\hline Average & $20.37-27.80$ & Less favourable \\
\hline Most & $27.81-35.25$ & Unfavorable \\
\hline
\end{tabular}

Based on the nature of the forecast, the need for dispensary observation, in the development of measures to eliminate the adverse effects of socio-hygienic and biomedical factors in this student is determined. Individual prognosis of digestive diseases in schoolchildren according to the developed matrix is proposed to be used during medical examinations of schoolchildren. To illustrate, which is given an example to determine the degree of risk of digestive diseases among schoolchildren on the basis of calculations of the prognostic index: a boy (33.7), class 9 (28.9), is brought up in a full family (12.5), the level of material security of the family is good (13.7), the number of working family members is two (20.34), the psychological microclimate of the family is favorable (13.7), housing conditions are good (13.6), smokes (31.1), alcohol uses (33.8), there are conflicts with classmates and schoolchildren (32.6), responds to conflict situations not paying attention or is upset not much and forgets quickly (13.6), eats in school, 1 time (22.41), eats regularly in the dining room (13.9), canteen not attending (33.8), parents allocate money for food at school (33.74). Vitamin and mineral complexes did not take (32.16), in matters of nutrition is partially informed (19.9), food intolerance is not (15.02), the presence of diseases among the next of kin is not (13.55), the risk of digestive diseases in this student is 24,9 . The risk of diseases of the digestive system the student is:

$$
\begin{gathered}
\sum X / \Sigma R=(33.7+28.9+12.5+13.7+20.3+13.7+13.6+31.1+33.8+32.6+13.6+22.4+13.9 \\
+33.8+33.74+32.16+19.9+15+13.5) / 19=22.73 .
\end{gathered}
$$

In this case, the forecast is less favorable, because the result is in the range of 20.37-27.80. The proposed method of forecasting allows a fairly simple way to identify persons representing a different degree of risk of diseases of the digestive system. In this final prognostic indicator determines the impact it can have any one or more of the significant components of the coefficients at the other value is unimportant. On this basis, the essence of individual measures and advice will be limited to specific activities aimed at eliminating or reducing the impact of these factors. Thus, the prognostic table and threshold values of the prognostic index developed by us allow to develop a complex of medical and social measures for the organization of prevention of the most common diseases of the digestive system among 
schoolchildren, which will allow to conduct targeted prevention, choosing its rational form. This aspect can lead to a sharp decrease in digestive diseases in schoolchildren, improve the condition of patients, obtain a significant medical and economic effect. The study showed that before the beginning of the complex of measures to eliminate (mitigate) adverse factors, no significant differences were found in both groups, the average number of negative factors per surveyed student was the same (respectively - 5.9:5.9; 6.6:6.5; 10.4:10.5). This significantly increases the average number of negative risk factors in the student depending on the forecast of 5.9-10.4 in the control group and 5.9-10.5 in the main group $(P<0.05)$ since the prediction during the observation period.

In accordance with the plan of measures to eliminate (weaken) adverse medical and social factors in schoolchildren with digestive diseases, in the main group there was a significant reduction in negative factors. Thus, if after 6 months of observation the number of negative factors in the main group decreased by one surveyed to 4.6, in the control group, where preventive measures were not distributed, this figure was 7.2 per student. After 12 months of follow-up in the main group, the number of adverse factors per student decreased to 3.9, after 18 months was 3.6, after 24 months - 3.5. At the same time, the number of unfavorable factors per one surveyed student in the control group in 12 months was 6.9 , in 18 months -6.8 , in 24 months decreased only to 6.7 (Table 3).

Table 3: The effectiveness of medical and social prevention of diseases of the digestive system in schoolchildren (the number of adverse factors in the dynamics)

\begin{tabular}{|c|c|c|c|c|c|c|c|c|c|c|c|c|}
\hline \multirow{3}{*}{$\begin{array}{l}\text { Group of } \\
\text { students }\end{array}$} & \multirow{3}{*}{$\begin{array}{l}\text { Total } \\
\text { number of } \\
\text { students } \\
\text { surveyed }\end{array}$} & \multicolumn{10}{|c|}{ Observation time } & \multirow{3}{*}{$\begin{array}{c}\text { The number of } \\
\text { exacerbations of } \\
\text { diseases of the } \\
\text { digestive system } \\
\text { in schoolchildren } \\
\text { per one } \\
\text { examined }\end{array}$} \\
\hline & & \multicolumn{2}{|c|}{$\begin{array}{c}\text { Before the start of } \\
\text { observation }\end{array}$} & \multicolumn{2}{|c|}{ After 6 months } & \multicolumn{2}{|c|}{ After 12 months } & \multicolumn{2}{|c|}{ After 18 months } & \multicolumn{2}{|c|}{ After 24 months } & \\
\hline & & $\begin{array}{c}\text { Total } \\
\text { number of } \\
\text { factors }\end{array}$ & $\begin{array}{l}\text { One of the } \\
\text { surveyed } \\
\text { accounts }\end{array}$ & $\begin{array}{c}\text { Total } \\
\text { number of } \\
\text { factors }\end{array}$ & $\begin{array}{l}\text { One of the } \\
\text { surveyed } \\
\text { accounts }\end{array}$ & $\begin{array}{c}\text { Total } \\
\text { number of } \\
\text { factors }\end{array}$ & $\begin{array}{l}\text { One of the } \\
\text { surveyed } \\
\text { accounts }\end{array}$ & $\begin{array}{c}\text { Total } \\
\text { number of } \\
\text { factors }\end{array}$ & $\begin{array}{l}\text { One of the } \\
\text { surveyed } \\
\text { accounts }\end{array}$ & $\begin{array}{c}\text { Total } \\
\text { number of } \\
\text { factors }\end{array}$ & $\begin{array}{l}\text { One of the } \\
\text { surveyed } \\
\text { accounts }\end{array}$ & \\
\hline Control & 78 & 556 & 7.1 & 561 & 7.2 & 544 & 6.9 & 536 & 6.8 & 529 & 6.7 & 3.7 \\
\hline Main & 97 & 675 & 7.0 & 447 & 4.6 & 387 & 3.9 & 354 & 3.6 & 347 & 3.5 & 1.6 \\
\hline Total & 175 & 1231 & 7.03 & 1000 & 5.76 & 931 & 5.32 & 890 & 5.08 & 876 & 5.0 & 2.7 \\
\hline
\end{tabular}

As can be seen from Table 1, in the main group of 675 unfavorable factors $(224+273+178)$ by the end of the followup period, 328 risk factors or $48.6 \%$ were eliminated (attenuated). In the control group, where these activities were not carried out in schoolchildren, of 556 unfavorable factors $(159+231+166)$ only 27 unfavorable factors were eliminated, i.e. by 4.9 per cent. In the main group, compared with the control group, the number of exacerbations of digestive diseases decreased by 2.3 times $(3.7: 1.6=2.3)$. At the same time, the average number of negative factors per student in the control group decreased by 1.1 times $(7.1: 6.7=1.0)$, the main -2 times $(7.0: 3.5=2)$ (Figure 2).

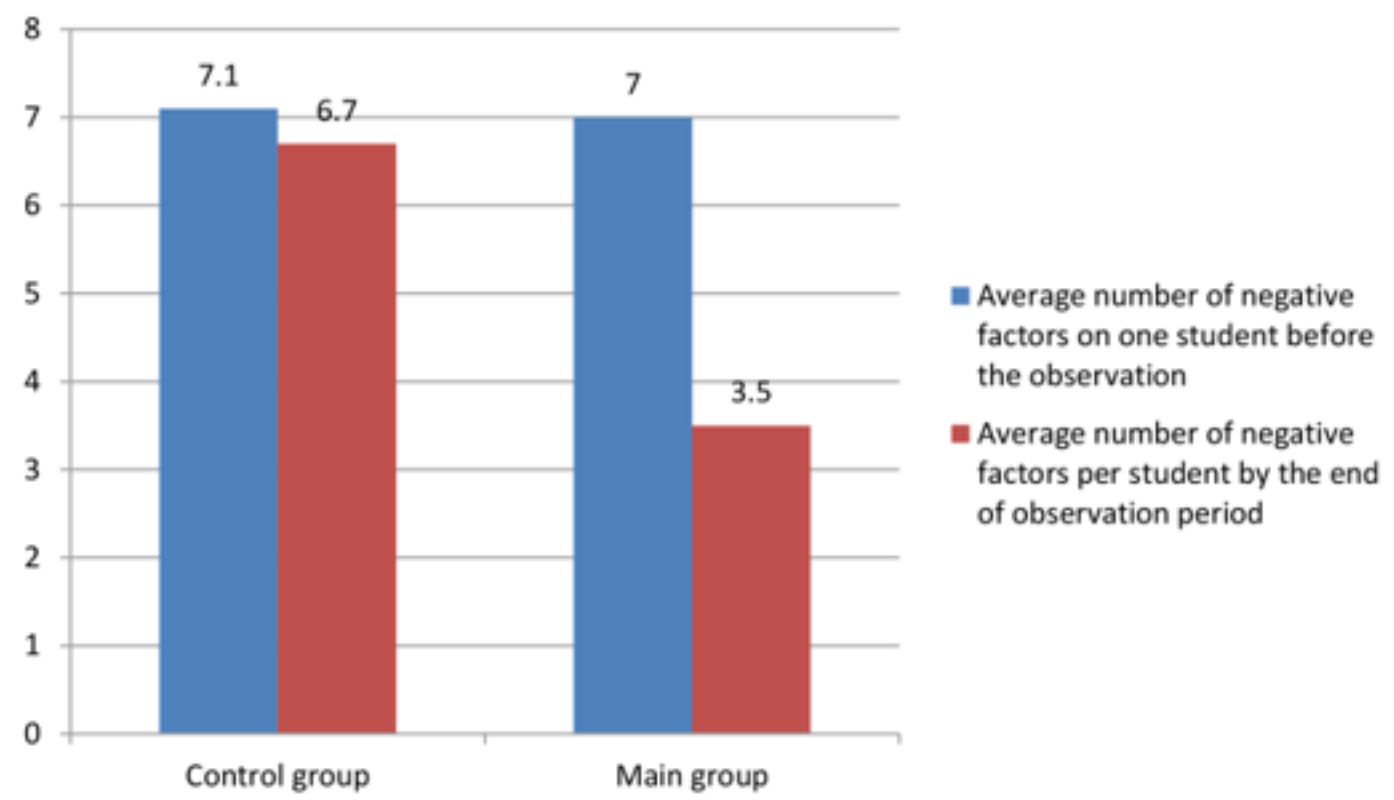

Figure 2: The results of the effectiveness of the prevention of diseases of the digestive system in schoolchildren of Shymkent 


\section{CONCLUSION}

Thus, the elimination of the influence of negative socio-hygienic, biomedical, behavioral factors and lifestyle in schoolchildren allowed to reduce the number of unfavorable factors by $48.6 \%$, reduce the exacerbation of diseases of the digestive system by 2.3 times compared with the control group.

Therefore, the measures developed by us for the prevention of diseases of the digestive system in schoolchildren allowed to obtain a significant preventive effect in reducing the frequency of exacerbations of diseases of the digestive system and increase the effectiveness of the school doctor, pediatrician, school for the improvement of students of this school.

\section{REFERENCES}

1. Buleshov MA, Omarova BA, Tuktibayeva SA. Features formation of indicators of children's health depending on the ecological state of residential areas. Astana medical journal, 2018;3(77):85.

2. Nurmieva AA. Medical and social aspects of the prevention of diseases of the digestive system among schoolchildren of Kazan: autoref. ass. prof. med. science A. A. Nurmieva. - Kazan, 2012.

3. Tutelyan VA, Koniya I, Kaganov BS (Ed.). Eating healthy and sick child. Dynasty, 2009.

4. Rodionov VA, Suslikov VL, Matveeva NA. Children's health in the territories of ecological and biogeochemical risk. Cheboksary: publishing house of the Chuvash. un-ta, 2003.

5. Baranov AA, et al. State of health of children as a factor of national security. ROS. pediatrician. Journal, 2005;2:48.

6. Abdullayeva DA, Kamilova AT, Akhmedova IM. The Incidence of digestive diseases in school-age children in the process of education. Actual problems of abdominal pathology in children: materials of the Jubilee XX international Congress of children's gastroenterologists of Russia and CIS countries. 2013:5-6.

7. Actual problems of Pediatrics: resolution XVI Congress of pediatricians of Russia. Russ. pediatrician journal, 2009;3:59-61.

8. Bogomolova ES, Leonov AV, Chekalova SA. Experience of regional monitoring of health of schoolchildren. Vestn. Grown. University of friendship of peoples. Ser. «Medicine», 2007;6:448-52.

9. Baranov AA. Children's gastroenterology: problems and problems at the present stage. Question of the modern pediatrics, 2008;5:1-9.

10. Altman DG, Linder J, Croppy K. Policy alternatives for reducing tobacco sales to minors: Results from a national sunny of retail chain and franchise stores. Pub. Health Pol., 2005;13:318-20. https://doi.org/10.2307/3342731 PMid:1401050

11. Altman DG, Foster V. Reducing the illegal sale of cigarettes to minors. JAMA, 2003;26:261-5. https://doi.org/10.1001/jama.1989.03420010090039 PMid:2908999

12. Carle AC. Reaching kids: partnering with preschools and schools to improve children's Health. Issue brief (Grantmakers Health), 2009;35:1-41.

13. Furuta $T$, et al. Polymorphish of interleukin-lbeta affects the eradicathion rates of Helicobacter pylori by triple therapy. Clin. Gas-troenterolol. Hepatol., 2004;2(1):22-30. https://doi.org/10.1016/S1542-3565(03)00288-X

14. Grimm W, Fischbach W. Helicobacter pylori infection in children and juveniles: an epidemiological study on prevalence, socio-economic factors and symptoms. Dtsch. Med. Wochenschr., 2003;128(37):1878-83. https://doi.org/10.1055/s-2003-42158 PMid:12970821

15. Rothenbacher D, Bode G, Brenner H. History of breastfeeding and Helicobacter pylori infection in pre-school children: results of a population-based study from Germany. J Epidemiol., 2002;31(3):632-7. https://doi.org/10.1093/ije/31.3.632 PMid:12055166

16. Schimberg GJ, Puller JP, Greenwald LM. Health care systems in countries. Health Off (Millwood), 2006;10:22-38. https://doi.org/10.1377/hlthaff.10.3.22 PMid:1748380

17. Seclona MK, et al. Bo obese children become obese adults. A review of the literature. Prev. Med., 2007;22:16777. https://doi.org/10.1006/pmed.1993.1014 PMid:8483856

18. Service RM. Patterns of change in weight / stature 2 from 2 to 18 years: findings from long-term serial data for children in the Fells Longitudinal Growth Study. Into J. Obes., 2009;15:479-85.

19. WHO. World health statistics 2005. Indicators online database. Geneva, World Health Organization, 2005. http://www3.who.int/statistics/. 
20. Adelshina EN. Medical and social characteristics of children of early and preschool age with diseases of the digestive system. Kazan: B. I., 2011.

21. Abanin AM. Scientific substantiation of health promotion of schoolchildren on the basis of the formation of a healthy lifestyle: autoref. ass. prof. med. Science. 2004.

22. Baranov AA, Kuchma VR, Sukhareva LM. Assessment of children's health. New approaches to preventive and recreational work in educational institutions. GEOTAR-Media, 2008.

23. Zakharova OV. Some actual problems of school food. School of health, 2000;2:37-42.

24. Ivanova AA, Yakovleva TV, Modestov AA. The main directions of modernization of the system of health improvement of children and adolescents. Russian pediatric journal, 2011;3:37-9.

25. Loranskaya TI, Vishnevskaya VV. Study of the motor function of biliary system and gastro-duodenal zone in the pathology of biliary tract. Russian medical journal, 2005;7(1):1-7.

26. Sukharev AG, Tsyrenova NM. Technology of education, promoting the health of children in modern school: teaching aid. MIOO. 2004.

27. Mingazova EN, et al. Standards of physical development of children in Kazan aged 0 to 17 years: Handbook. Kazan: RIC "School", 2002.

28. Setko IM, Sosnina EV. The Role of nutrient security in the formation of nutritional status and reserve capacity of the organism of schoolchildren. Hygiene and sanitation, 2009;4:45-6.

29. Bulatov VP, et al. Early diagnosis and optimization of therapy of gastroduodenal pathology in children. Children's hospital, 2003;4:34-6.

30. Michaluk NC. Age characteristics of child nutrition. Issues of nutrition, 2005;74(2):33-6.

31. Tuktibayeva SA, Kemelbekov KS, Kuandykova AK, Amirkhankyzy A, Shukuralieva D. Dynamics of changes in the general morbidity in children and adolescents in the city of Turkestan (Kazakhstan). Modern medicine: new approaches and current research: proceedings of the stat.on mater. XI-international. science-prakt. Conf., 2018;5(10):62-71.

32. Golubev VV. Fundamentals of Pediatrics and hygiene of preschool children. Moscow: Academy, 2003.

33. Buleshov MA, Tachkulieva BB, Turlybek DK, Turalieva LB. Ways to improve continuity in the organization of curative preventive care to children in a large city. Bulletin of South-Kazakhstan pharmaceutical Academy, 2013;2(63):67.

34. Ospanova GK. Health of children and adolescents in Almaty. Pediatrics and pediatric surgery, 2008;3:18-9.

35. Health of the population of the Republic of Kazakhstan and the activities of health organizations in 2017. Astana: Globe, 2018.

36. Tleuzhan RT. The structure of morbidity of children under 14 years in rural regions. Bulletin of South Kazakhstan medical Academy, 2010;3:15-7.

37. Elebekova GK. Hygienic bases of adaptation of repatriate's school age to Shymkent ecosystem: autoref. ass. prof. med. science: 14.00.07 - Hygiene. Almaty: Kazakh state medical Institute. S. D. Asfendiyarova, 2008.

38. Onishchenko GG. Sanitary and epidemiological welfare of children and adolescents: the state and ways of solving problems. Hygiene and sanitation, 2007;4:53-9.

39. Baranov AA, Albitsky VYu. Social and organizational problems of Pediatrics. Selected essays. Publishing House "Dynasty", 2003.

40. Vasilevskaya LS, Oknyansky LG. Physiological basis of nutrition. Issues of nutrition, 2002;2:42-5.

41. Zakharova OV. Some actual problems of school food. School of health, 2000;2:37-42.

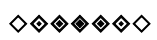

http://www.ejgm.co.uk 